\title{
Abnormal expression of GADD45B in human colorectal carcinoma
}

\author{
Lisha Wang ${ }^{1,2,3 \dagger}$, Xiuying Xiao ${ }^{1,2,5+}$, Dali $\mathrm{Li}^{1,2,3}$, Yayun Chi ${ }^{6}$, Ping Wei ${ }^{1,3}$, Yiqin Wang ${ }^{1,2,3}$, Shujuan $\mathrm{Ni}^{1,2,3}$, Cong Tan ${ }^{1,2,3}$,
} Xiaoyan Zhou ${ }^{1,2,3}$ and Xiang Du 1,2,3, $^{*}$

\begin{abstract}
Background: GADD45B is a member of the growth arrest DNA damage-inducible gene family associated with cell growth control, apoptosis, and DNA damage repair response. The aim of this study is to detect the role of GADD45B in colorectal carcinoma (CRC); the area not studied in depth to date.

Methods: The mRNA and protein levels of GADD45B were examined by Real-Time quantitative PCR (RT-qPCR) and immunohistochemistry (IHC) in CRC tissues and adjacent noncancerous tissues (ANCT). Over-expression plasmids and SiRNA were used to regulate GADD45B expression in CRC cell lines in vitro and flow cytometry and Western blotting were used to detect apoptotic changes.

Results: The mRNA and protein levels of GADD45B were significantly higher in CRC tissues than those in ANCT $(P<0.05)$. Up-regulation of GADD45B was also correlated with relapse and death of CRC patients $(P<0.05)$. The Kaplan-Meier survival curves indicated that disease-free survival (DFS) was significantly worse in CRC patients who showed GADD45B overexpression. A Cox multivariate analysis revealed that GADD45B overexpression and TNM stage were significant factors affecting patients' survival. On the other hand, as a tumor suppressor gene, GADD45B amplified from normal colorectal tissues could induce apoptosis in CRC cell lines and may be associated with the p53-mediated apoptotic pathways.

Conclusion: GADD45B, a tumor suppressor gene potentially through the p53-mediated apoptotic pathways, is paradoxically overexpressed in CRC and as such may play an unappreciated role in tumorigenesis. The exact mechanism of GADD45B inactivation and overexpression requires further investigation. GADD45B could be a potential therapeutic target for CRC treatment in future.
\end{abstract}

Keywords: Colorectal carcinoma, GADD45B, Carcinogenesis, Relapse

\section{Background}

CRC is one of the most common malignancies worldwide [1]. Many risk factors, such as inflammatory bowel disease, inherited syndrome, diets low in fiber, smoke, obesity, and heavy alcohol use, are related to intestinal mucosa injury and dysplasia, and may result in carcinogenesis of CRC [2,3]. However, the potential molecular mechanisms of DNA damage from these exposures are unknown. The development of CRC is a long and

\footnotetext{
*Correspondence: dx2008cn@yahoo.com.cn

${ }^{\dagger}$ Equal contributors

'Department of Pathology, Fudan University Shanghai Cancer Center, Shanghai 200032, China

${ }^{2}$ Department of Oncology, Shanghai Medical College, Fudan University, Shanghai 200032, China

Full list of author information is available at the end of the article
}

complicated process, including the activation of multiple oncogenes and the inactivation of tumor suppressor genes.

GADD45B is a member of the growth arrest DNA damage-inducible gene (GADD45) family, which is composed of GADD45A (GADD45), GADD45B (MYD118), and GADD45G (cytokine response gene 6). This gene family encodes small $(18 \mathrm{kDa})$, evolutionarily conserved proteins, sharing homology and high acidity [4]. GADD45B was previously identified as a primary response gene in myeloid differentiation activated by interleukin-6 in the mouse myeloid leukemia cell line M1, which is associated with cell growth control, apoptosis, and cellular responses to DNA damage [5]. Recent studies have reported that GADD45B may play an

\section{Biomed Central}

(c) 2012 Wang et al.; licensee BioMed Central Ltd. This is an Open Access article distributed under the terms of the Creative Commons Attribution License (http://creativecommons.org/licenses/by/2.0), which permits unrestricted use, distribution, and reproduction in any medium, provided the original work is properly cited. 
important role in the carcinogenesis of human hepatocellular carcinoma and pituitary gonadotrope tumors [6-8], but its role in CRC remains unclear. Therefore, we examined both the mRNA and protein expression of GADD45B, correlated the results with clinicopathologic characteristics of CRC patients, and detected GADD45B-induced apoptosis in CRC cell lines.

\section{Methods}

\section{Patient samples}

RNAlater-preserved solid tissues, formalin-fixed paraffinembedded (FFPE) archival CRC tissues and ANCT were obtained from Fudan University Shanghai Cancer Center between 2005 and 2008. The tumors were assessed according to the WHO classification by two academic gastrointestinal pathologists. The inclusion criteria were as follows: colorectal adenocarcinoma (excluding mucinous carcinoma); no preoperative chemotherapy or radiotherapy; primary sporadic tumors. This study was approved by the Ethical Committee of Fudan University Shanghai Cancer Center for Clinical Research. The written informed consents were obtained from all the patients.

\section{Cell culture and reagents}

Dulbecco's Modified Eagle's Medium (DMEM), Roswell Park Memorial Institute (RPMI) 1640 medium, penicillin, streptomycin, Fetal Bovine Serum (FBS), trypsin-EDTA (Ethylene Diamine Tetraacetic Acid) and Phosphate Buffered Saline (PBS) were purchased from GIBCO BRL (USA). Three human CRC cell lines, including LoVo, SW620, and SW480 were purchased from American Type Culture Collection (ATCC). LoVo (poorly differentiated) and SW620 (highly metastatic) were cultured in high glucose DMEM with 10\% FBS, 100 units/ml penicillin and $100 \mu \mathrm{g} / \mathrm{ml}$ streptomycin. SW480 (highly differentiated) was cultured in RPMI 1640 supplemented with $10 \% \mathrm{FBS}, 100$ units $/ \mathrm{ml}$ penicillin, and $100 \mu \mathrm{g} / \mathrm{ml}$ streptomycin. All cells were cultured in a $5 \% \mathrm{CO}_{2}$ incubator at $37^{\circ} \mathrm{C}$. The primary antibodies GADD45B (H-70), P53 (DO-1), Bcl-2 (100), Bax (N-20), and caspase-3 p20 (N-19) were purchased from Santa Cruz Biotechnology; $\beta$-actin (13E5), cleaved PARP (Asp 214) and the secondary antibodies (horseradish peroxidase-linked anti-mouse immunoglobulin G, and anti-rabbit immunoglobulin G) were purchased from Cell Signaling Technology.

\section{RNA extraction and quantitative analysis of GADD45B}

Total RNA was extracted from 64 pairs of CRC tissues, ANCT, and cultured CRC cells using TRIzol reagent (Invitrogen, Carlsbad, CA, USA) following the manufacturer's instructions. The structural integrity of the total RNA was confirmed by electrophoresis on $1 \%$ agarose gels. The first strand of cDNA was reverse-transcribed from 500 ng total RNA in $20 \mu$ using the cDNA Synthesis Kit (Tiangen Biotech Co., Ltd., Beijing). GAPDH was used as an endogenous control. The cycling conditions for GAPDH and GADD45B were as follows: one cycle of $95^{\circ} \mathrm{C}$ for 5 minutes; 40 cycles of $95^{\circ} \mathrm{C}$ for 20 seconds, $58^{\circ} \mathrm{C}$ for 30 seconds, and $68^{\circ} \mathrm{C}$ for 45 seconds; and one cycle of $72^{\circ} \mathrm{C}$ for 10 minutes. The specificity of amplification was validated by a single peak in the melting curves. The GADD45B gene was amplified with the following primes: $5^{\prime}$-TGA CAA CGA CAT CAA CAT C-3' (the forward primer) and 5'-GTG ACC AGA GAC AAT GCA G-3' (the reverse primer). The endogenous GAPDH gene was amplified with the following primers: 5 -GAA AGT CCG GAA GTC TCT GG-3' (the forward primer) and $5^{\prime}$-TAG AGA CTT GGG CAG TGT GG-3' (the reverse primer). The standard curves for GAPDH were generated using serial dilutions. Each RT-qPCR cycle was repeated three times to confirm the results.

\section{IHC analysis}

152 FFPE blocks of CRC tissues and ANCT were collected for tissue microarrays. Two CRC tissue cores and two ANCT cores from the same patient's FFPE blocks were arranged on a recipient paraffin block (with a $1 \mathrm{~mm}$ core per specimen). 5 - $\mu \mathrm{m}$ thick paraffin sections were deparaffinized in xylene and rehydrated in a graded alcohol series, boiled with $10 \mathrm{mmol} / \mathrm{L}$ of citrate buffer ( $\mathrm{pH} \mathrm{6)}$ for $15 \mathrm{~min}$, treated with $0.3 \% \mathrm{H}_{2} \mathrm{O}_{2}$ for $10 \mathrm{~min}$, and preincubated in blocking solution $(10 \%$ normal goat sera) for $1 \mathrm{~h}$ at room temperature. The steps were performed using the Envision two-step method. The Envision and DAB Color Kit was purchased from Gene Tech (Shanghai) Company Limited. The GADD45B rabbit anti-human polyclonal antibody was used at a 1:500 dilution. PBS was used as a negative control.

Tissue microarray slides were concurrently evaluated by 2 of the authors. A granular cytoplasmic stain was assessed as positive. Briefly, the staining index (SI, range $0-9)$ was considered as the product of the intensity score (0, no staining; $1+$, faint/equivocal; $2+$, moderate; $3+$, strong) and the distribution score ( 0 , no staining; $1+$, staining of $<10 \%$ of cells; $2+$, between $10 \%$ and $50 \%$ of cells; and $3+$, staining of $>50 \%$ of cells). For GADD45B protein in this study, a moderate/strong cytoplasm staining of (SI = 3-9) was defined as positive staining, while a weak or negative staining $(\mathrm{SI}=0-2)$ was defined as negative staining $[9,10]$.

\section{Construction of pEGFP-N1-GADD45B}

cDNA from normal colorectal tissues was amplified by PCR. The PCR product and the pEGFP-N1 plasmid vector were double digested with BglII/Sall enzymes and then ligated using T4 DNA ligase. The ligated product 
was transformed into Escherichia coli DH5 $\alpha$ competent cells, coated to the LB solid medium containing kanamycin $(100 \mathrm{ug} / \mathrm{ml})$, and stored at $37^{\circ} \mathrm{C}$ overnight. A selection of white colonies was amplified using the PCR reaction, and the positive clone was incubated in a LB liquid medium (kanamycin $100 \mathrm{ug} / \mathrm{ml}$ ) with agitation overnight. The recombinant plasmid was extracted the next day. Identification of the correct plasmid was sent to Shanghai R\&S Biotechnology for sequencing. The result of DNA sequencing was consistent with the PubMed database. The plasmid sequence was named pEGFP-N1-GADD45B. SW480 (3*10 $10^{5}$ cells/dish) were transplanted into $35 \mathrm{~mm}$ dishes 1 day before transfection. After $70 \%$ confluence was reached, $2 \mu \mathrm{g}$ of plasmid DNA was diluted with $100 \mu \mathrm{l}$ serum-free medium (without antibiotics). The transfection complex was then formed by adding the FuGENE ${ }^{\circledR}$ HD Transfection Reagent (Roche Diagnostics, Mannheim, Germany) to the tube containing the diluted DNA. The transfection complex was mixed and incubated for 15 minutes at room temperature. The mixture was then added to each dish (there is no need to remove the old medium and replace it with fresh medium) and stored in a $5 \% \mathrm{CO}_{2}$ incubator at $37^{\circ} \mathrm{C}$.

\section{SiRNA synthesis}

Small interfering RNA (SiRNA) duplexes were synthesized and tested for the specific inhibition of GADD45B expression. SW620 ( $3 * 10^{5}$ cells/dish) were transplanted into $35 \mathrm{~mm}$ dishes 1 day before transfection. After $70 \%$ confluence was achieved, 100 pmol Si-GADD45B (purchased from Shanghai GenePharma Co., Ltd.) was diluted with $100 \mu \mathrm{l}$ serum-free medium using the FuGENE $^{\circledR}$ HD Transfection Reagent, according to the manufacturer's instructions.

\section{Cell apoptosis analysis}

The induction of apoptosis by Si-GADD45B and pEGFP-N1-GADD45B in SW620 and SW480 was determined by flow cytometry using the Annexin V-FITC Apoptosis Detection Kit. Briefly, $3^{*} 10^{5}$ cells were plated and treated with Si-GADD45B and pEGFP-N1GADD45B for 24 hours. The cells were then harvested, washed in PBS, and incubated with Annexin V and propidium iodide in a binding buffer in the dark at room temperature for 10 minutes. The stained cells were analyzed using the Beckman Coulter Flow Cytometer.

\section{Western blotting analysis}

Whole cell lysates were generated using the cell lysis solution, followed by centrifugation and the collection of the supernatant fraction for immunoblotting. Proteins were separated using SDS-PAGE gel electrophoresis and transferred onto a nitrocellulose membrane. After blocking with 5\% non-fat milk in blocking buffer (20 mmol/l of PBS containing 0.1\% Tween 20), the membrane was incubated with the primary antibody at $4^{\circ} \mathrm{C}$ overnight and incubated with the appropriate horseradish peroxidase-conjugated secondary antibodies the next day for 1 hour at room temperature. The immunoreactive bands were visualized using the ECL Plus Western Blotting Detection System. The level of $\beta$-actin for each sample was used as a loading control.

\section{Statistical analysis}

The experimental data were expressed as the mean \pm standard deviation, and the statistical significance between different groups was determined using t-tests. The relationship between GADD45B expression and clinicopathological features of CRC patients was analyzed using $X^{2}$ and Fisher's exact tests. Statistical significance was defined as a P-value less than 0.05 .

\section{Results}

Quantitative analysis of GADD45B mRNA expression

GADD45B and GAPDH mRNA expression was calculated using the absolute quantification method according to the parameter threshold cycle $(\mathrm{Ct})$ and gene copy numbers [11]. Melting curves of GADD45B and GAPDH with single peaks indicated good specificity. The standard curve formulas, $\mathrm{Y}=35.9-4.555 \mathrm{X}\left(\mathrm{r}^{2}=0.999\right)$, for GAPDH was derived from the lines of the calibration curves. The average amount of GADD45B mRNA in CRC tissues was significantly higher than that in ANCT $(P<0.05$, Table 1$)$.

\section{IHC analysis of GADD45B protein expression}

In the IHC analysis, positive staining of GADD45B protein was noted in 109 of the 152 (69.1\%) paraffinembedded CRC tissues, while negative staining was

Table 1 GADD45B expression in CRC tissues and ANCT

\begin{tabular}{llllllll}
\hline & $\mathbf{n}$ & GADD45B mRNA & $\boldsymbol{P}$ & $\mathbf{n}$ & \multicolumn{2}{c}{ GADD45B protein } & \multicolumn{2}{c}{$\mathbf{X}^{\mathbf{2}}$} & & Positive & Negative \\
\hline CRC & 64 & $23625.6 \pm 4028.1^{a}$ & $<0.05$ & 152 & $105(69.1 \%)$ & $47(30.9 \%)$ \\
\hline ANCT & 64 & $21318.2 \pm 4549.9$ & & 152 & $46(30.3 \%)$ & $106(69.7 \%)$ & 0.000 \\
\hline
\end{tabular}

${ }^{a}$ gene copy numbers using SYBR Green. 
noted in the remaining cases $(30.3 \%, 46$ of $152, P<0.05)$ (Table 1, Figure 1). Table 2 summarizes the correlation of GADD45B expression with the clinicopathological features of CRC patients. The age of patients ranged from 29 to 75 years with a median age of 63 years;
$54.6 \%$ were men (83 of 152), and $45.4 \%$ were women $(69$ of 152). GADD45B expression was not correlated with patients' sex, age, tumor size, location, gross type, differentiation and TNM stage. The up-regulation of GADD45B was correlated with the relapse and status

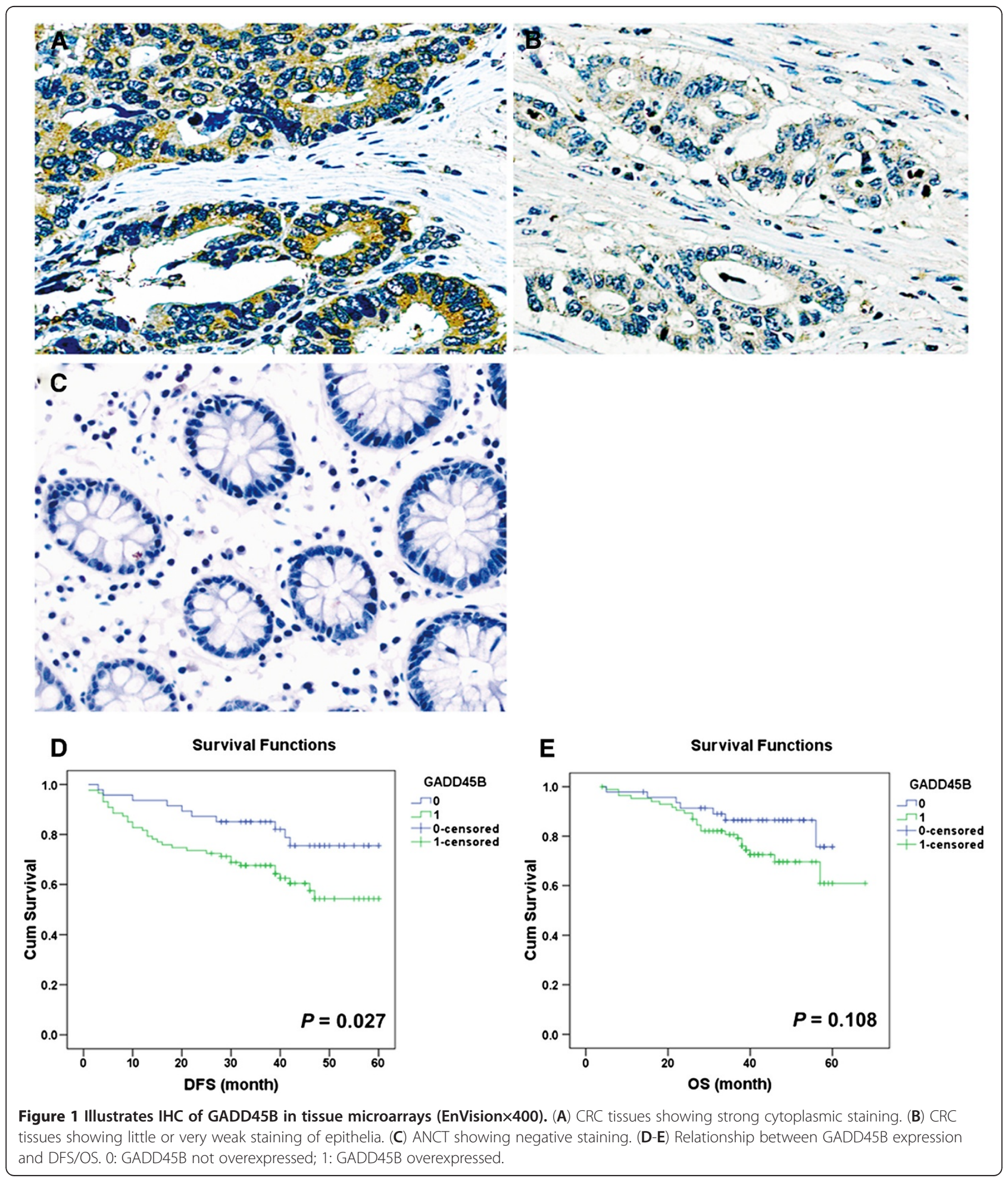


Table 2 Relationship between GADD45B expression and clinicopathological features in CRC patients

\begin{tabular}{|c|c|c|c|c|}
\hline Clinicopathological features & n & GADD45B n (\%) & $x^{2}$ & $P$ \\
\hline Gender & & & 0.116 & 0.734 \\
\hline Male & 83 & $59(71.1 \%)$ & & \\
\hline Female & 69 & $46(66.7 \%)$ & & \\
\hline Age (years) & & & 0.400 & 0.527 \\
\hline$<60$ & 93 & $66(71.0 \%)$ & & \\
\hline$>=60$ & 59 & $39(66.1 \%)$ & & \\
\hline Tumor size $(\mathrm{cm})$ & & & 0.079 & 0.779 \\
\hline$<5$ & 88 & $60(68.2 \%)$ & & \\
\hline$>=5$ & 64 & $45(70.3 \%)$ & & \\
\hline Location & & & 3.143 & 0.076 \\
\hline Colon & 101 & $65(64.4 \%)$ & & \\
\hline Rectum & 51 & $40(78.4 \%)$ & & \\
\hline Gross type & & & 0.055 & 0.973 \\
\hline Massive & 57 & $42(70.0 \%)$ & & \\
\hline Ulcerative & 81 & $57(68.7 \%)$ & & \\
\hline Invasive & 8 & $6(66.7 \%)$ & & \\
\hline Differentiation & & & 2.280 & 0.320 \\
\hline Well & 5 & $3(60 \%)$ & & \\
\hline Moderate & 113 & $75(66.4 \%)$ & & \\
\hline Poor & 34 & $27(79.4 \%)$ & & \\
\hline TNM stage & & & 2.114 & 0.146 \\
\hline$\|$ & 87 & 56 (64.4\%) & & \\
\hline III & 65 & 49 (75.4\%) & & \\
\hline Relapse & & & 5.390 & 0.020 \\
\hline Yes & 47 & 37 (78.7\%) & & \\
\hline No & 90 & 53 (58.9\%) & & \\
\hline Status & & & 4.269 & 0.039 \\
\hline Survival & 102 & 62 (60.8\%) & & \\
\hline Death & 35 & 28 (80.0\%) & & \\
\hline
\end{tabular}

(survival or death) of CRC in patients $(P<0.05)$. Patients with higher GADD45B expression tended to have a higher risk of relapse and death.

All patients were followed up for at least 4 years. After 4 years, 102 patients were still alive, 35 patients succumbed to the disease, and 15 patients declined to continue the participation in the study. The median survival time of CRC patients was 48 months. DFS was significantly worse in CRC patients with GADD45B overexpression than in patients that did not overexpress GADD45B $(P=0.027$, Figure 1D, 1E, Table 3$)$. As shown in Table 3 , stage $\amalg$ patients were also significantly associated with a poorer DFS $(P=0.013)$ compared with stage II patients. To assess whether GADD45B and TNM stage could be used as independent prognostic factors or not, a Cox model was generated using univariate analysis. The results indicated that combined analysis
Table 3 Univariate regression model of prognostic covariates in CRC patients

\begin{tabular}{lccccc}
\hline Characteristics & \multicolumn{2}{c}{ DFS } & & \multicolumn{2}{c}{ OS } \\
\cline { 2 - 3 } & $\mathbf{X} \mathbf{2}$ & $\boldsymbol{P}$ & & $\mathbf{X}$ & $\boldsymbol{P}$ \\
\hline Sex & 0.835 & 0.361 & 0.973 & 0.324 \\
\hline Age & 0.104 & 0.747 & 1.716 & 0.190 \\
\hline Location & 0.160 & 0.689 & 0.017 & 0.897 \\
\hline Size & 0.020 & 0.888 & 0.207 & 0.649 \\
\hline Gross type & 0.832 & 0.660 & 0.322 & 0.851 \\
\hline Differentiation & 3.939 & 0.140 & 1.972 & 0.373 \\
\hline TNM & 6.155 & $\mathbf{0 . 0 1 3}$ & 1.793 & 0.181 \\
\hline GADD45B expression & 4.915 & $\mathbf{0 . 0 2 7}$ & 2.586 & 0.108 \\
\hline Abbravian
\end{tabular}

Abbreviations: DFS disease free survival, OS overall survival.

The results represent poorer DFS in stage III patients and GADD45Boverexpressed patients.

of GADD45B and TNM stage was of statistically significance $\left(X^{2}=9.979, P=0.007\right)$.

\section{Detection of GADD45B background expression in CRC cell lines}

RT-qPCR was used to qualify GADD45B expression in different CRC cell lines, including LoVo, SW480, and SW620. As shown in Figure 2A, mRNA expression of GADD45B was the highest in SW620, the lowest in SW480, and moderate in LoVo. Therefore, in the following work, we chose SW480 for overexpression experiments and SW620 for inference experiments.

\section{Successful construction of pEGFP-N1-GADD45B and synthesis of Si-GADD45B}

To determine whether the construction of pEGFP-N1GADD45B was successful, the recombinant plasmid was verified using PCR and electrophoresis. In the $483 \mathrm{bp}$ location, there were evident bands of the PCR products. Meanwhile, the pEGFP-N1-GADD45B plasmid structure was also confirmed by double-enzyme cleavage (BgII/SaI enzyme) and gene sequence analysis. Two aim bands, at $4.7 \mathrm{~kb}$ and $483 \mathrm{bp}$, were acquired. After the successful
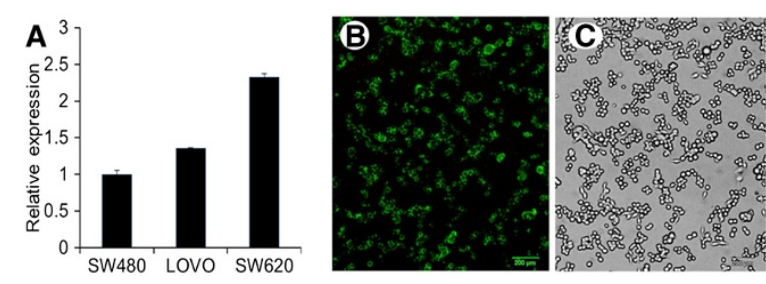

Figure 2 Displays GADD45B expression in CRC cell lines and transfection efficiency. (A) GADD45B expression was different in three CRC cell lines: highest in SW620, lowest in SW480, and moderate in LoVo. (B-C) Fluorescent (GFP) image and bright field image (the same area) of SW620 at $24 \mathrm{~h}$ after transfection under converted fluorescent microscopy. 
construction of pEGFP-N1-GADD45B and the chemical synthesis of the Si-GADD45B duplexes, plasmid DNA and Si-RNA were transfected into CRC cell lines. The transfection efficiency was between $70 \%$ and $80 \%$, as assessed with converted fluorescent microscopy (Figure 2B, 2C).

\section{Apoptosis analysis in human CRC cells}

To determine whether the overexpression or inhibition of GADD45B in CRC cells was associated with the induction of apoptosis, SW480 and SW620 cells were treated with pEGFP-N1-GADD45B and Si-GADD45B as described above. The numbers of apoptotic cells were assessed using the Annexin V-FITC Apoptosis Detection kit. Transfection with Si-GADD45B in SW620 for 24 hours resulted in a significant decrease of apoptotic cells (Figure 3A, 3B); while transfection with pEGFP-N1GADD45B in SW480 for 24 hours resulted in a significant increase of apoptotic cells (Figure 3C, 3D). This indicated that pEGFP-N1-GADD45B could effectively induce apoptosis in CRC cell line, while Si-GADD45B had the opposite effect $(P<0.05$, Figure 3E, 3F).

\section{Expression of apoptosis-related proteins by Western blotting}

Transfection of CRC cells with pEGFP-N1-GADD45B resulted in an increase in GADD45B, while transfection with Si-GADD45B showed a decrease in GADD45B (Figure 4A). Early studies showed that p53 can bind the
Bax gene promoter region and regulate Bax gene transcription $[12,13]$. The $\mathrm{Bcl}-2$ protein family plays a critical role in the regulation of apoptosis [14]. Because we observed apoptotic changes in CRC cells, we analyzed the levels of P53, Bax and Bcl-2 in cells treated with pEGFP-N1-GADD45B and Si-GADD45B, respectively. SW480 transfected with pEGFP-N1-GADD45B showed an increase in the level of P53 and Bax protein, with a concomitant decrease in the level of Bcl-2, when compared with the control cells. SW620 transfected with Si-GADD45B showed a decrease in the level of P53 and Bax protein, with a concomitant increase in the level of Bcl-2 (Figure 4A).

Caspase-3, as a critical executioner of apoptosis, cleaves a broad spectrum of cellular target proteins, including nuclear PARP that leads to a cell death cascade [15]. To clarify how the apoptotic pathway was activated by GADD45B, we examined the effects of pEGFP-N1GADD45B on the activation of Caspase-3 and PARP. Transfection with pEGFP-N1-GADD45B in SW480 resulted in an obvious increase in the cleavage of PARP and a decrease in unactivated caspase-3 (Figure 4A). This indicates that the canonical mitochondrial apoptotic pathway may be activated by pEGFP-N1GADD45B.

In addition, expression of these apoptosis-related proteins was also detected in CRC tissues. In paired CRC tissues and ANCT, apoptosis-related proteins expressed differently (Figure 4B). P53 and Caspase-3 has the

\section{A}

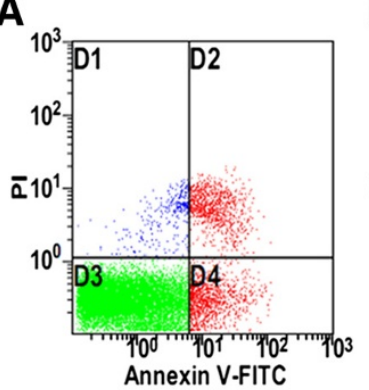

B
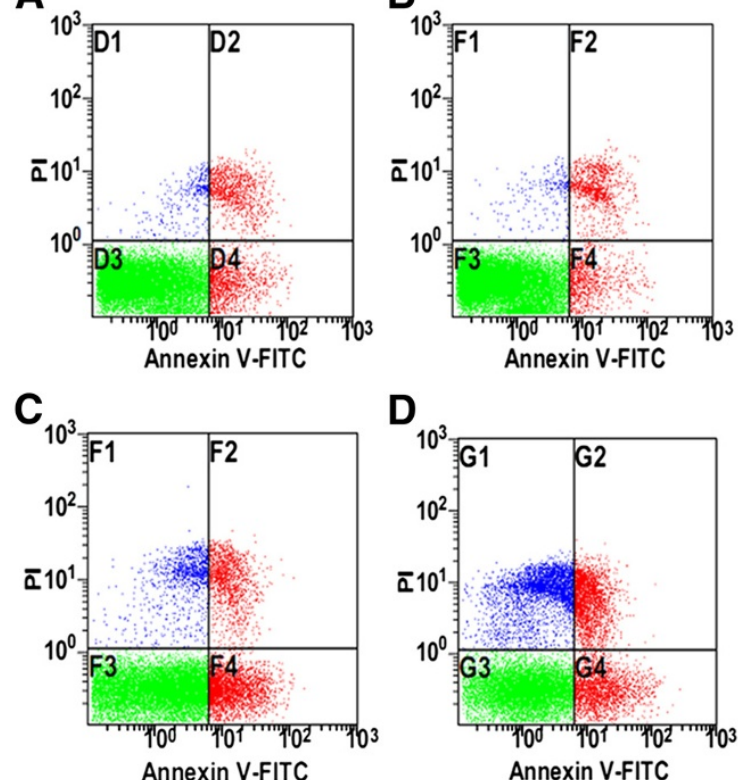

D

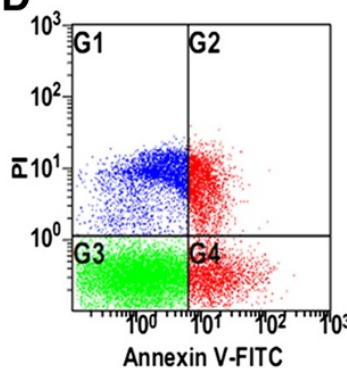

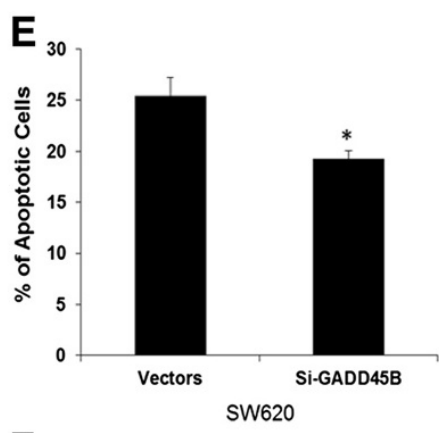

$\mathbf{F}$

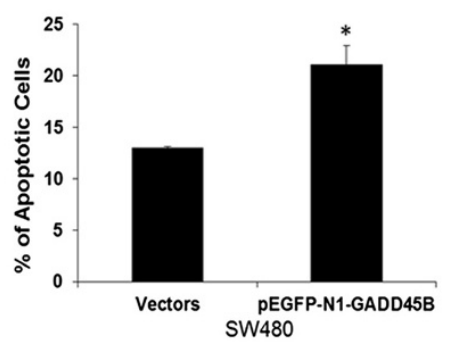

Figure 3 Shows induction of apoptosis in human CRC cell lines. (A) Apoptosis assay in SW620 transfected with vectors as control. (B) Apoptosis assay in SW620 transfected with Si-GADD45B. (C) Apoptosis assay in SW480 transfected with vectors as control. (D) Apoptosis assay in SW480 transfected with pEGFP-N1-GADD45B. (E-F) Apoptotic changes in SW620 and SW480 after transfection. * indicates P<0.05. 


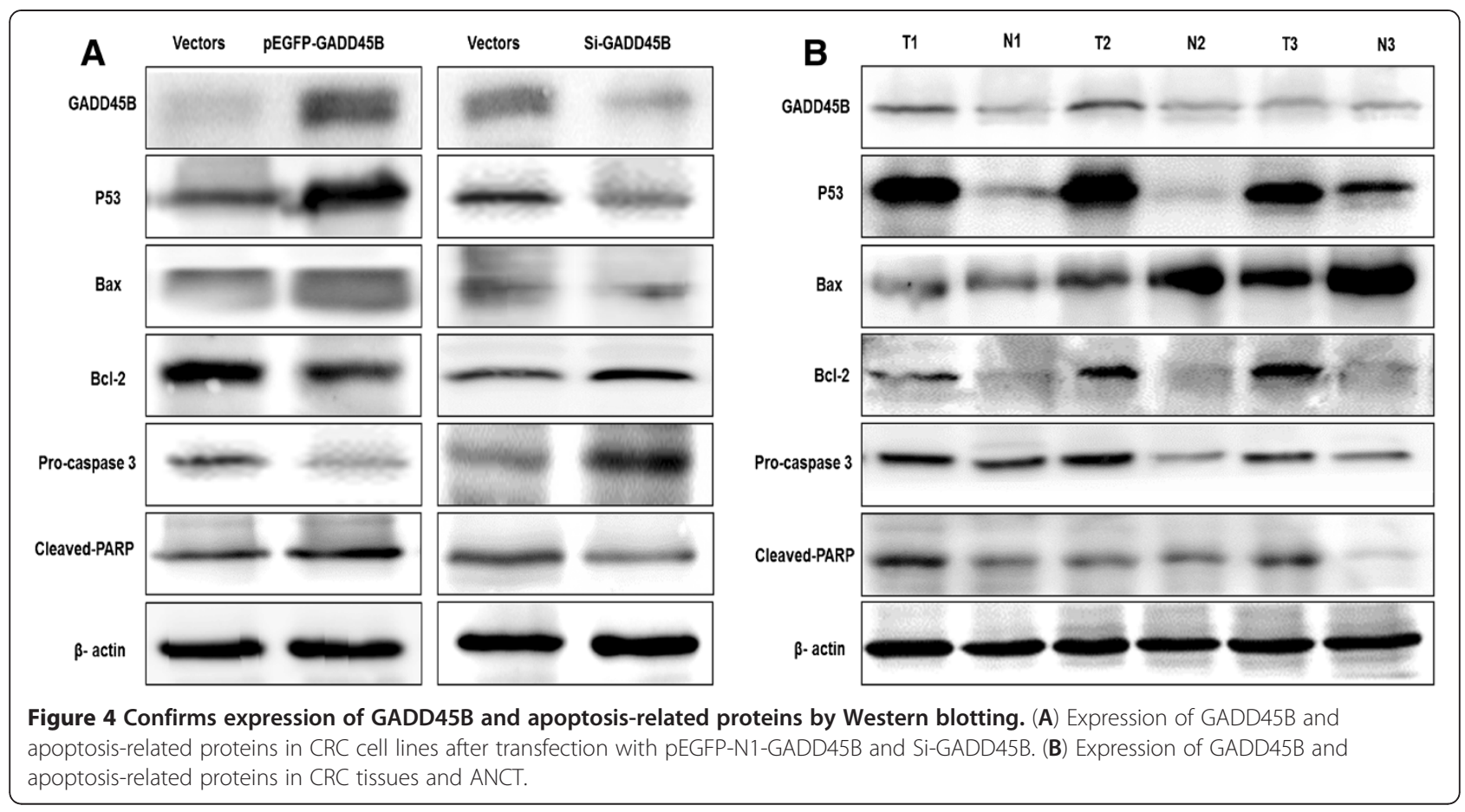

similar change trend with GADD45B, indicating similar implications for prognosis.

\section{Discussion}

CRC carcinogenesis is a complicated and multifactorial process resulting from many environmental exposures. This process involves the combined actions of multiple oncogenes and tumor suppressor genes [16]. As a negative growth-control gene, GADD45B is implicated in DNA damage, cell cycle arrest, and apoptosis. According to reports in the literature, higher expressions of GADD45B are associated with a higher risk of recurrence based on a cluster analysis of patients with stage II/III colon cancer treated with surgery alone or surgery plus adjuvant fluorouracil plus leucovorin [17]. Our study was consistent with the above research. To investigate the role of GADD45B in CRC, we first detected GADD45B expression in 64 pairs of CRC and ANCT by RT-qPCR. The results indicated that GADD45B was significantly up-regulated in CRC. Tissue microarrays are reliable tools for the clinicopathological characterization of cancer tissues $[18,19]$. The IHC analysis in 152 CRC patients using tissue microarrays further confirmed the results of the RT-qPCR and also observed that up-regulation of GADD45B expression was correlated with relapse and death in CRC patients $(P<0.05)$. The patients with higher GADD45B expression tended to have a higher risk of relapse and death. The KaplanMeier survival curves indicated that DFS was significantly worse in CRC patients that overexpressed GADD45B. A
Cox multivariate analysis revealed GADD45B expression and TNM stage as significant factors affecting survival. GADD45B overexpression in patients and stage III patients were significantly associated with a poorer DFS $(P<0.05)$. Therefore, we postulated that abnormal expression of GADD45B might be involved with the carcinogenesis of CRC and it showed potential for use as a prognostic marker in future.

Until now, the GADD45 gene family, including GADD45A, GADD45B and GADD45G, has been recognized as stress sensors that modulate the response of mammalian cells to genotoxic and physiological stresses and the process of tumor formation and progression [4,20-22]. GADD45B shares the common functions of the GADD45 family, including the regulation of cell growth, cell apoptosis, cellular responses to DNA damage and anti-tumor immune responses [23-25]. The overexpression of GADD45B has been shown to inhibit cell growth in a variety of human tumor cell lines, including hepatocellular carcinoma cells, prostate cancer cells, breast cancer cells and others [26-28]. To investigate the function of GADD45B in CRC, we constructed a pEGFP-N1-GADD45B vector, synthesized SiRNA duplexes, and then respectively transfected them into three CRC cell lines. After successful transfection with high efficiency, we performed an analysis of cell apoptosis using the flow cytometric method. Compared with the control group, the cells transfected with pEGFP-N1GADD45B had more apoptotic cells, whereas the cells transfected with Si-GADD45B had fewer apoptotic cells. 
We also investigated the effects of pEGFP-N1-GADD45B and Si-GADD45B on the expression of apoptosis-related proteins in CRC cells by Western blotting and found that the mitochondrial apoptotic pathway was activated by GADD45B. Therefore, as a tumor suppressor gene, GADD45B could induce apoptosis in CRC cell lines. According to the results of RT-qPCR and IHC, we presumed that GADD45B might lose its normal functions and promote carcinogenesis in CRC tissues. This inconsistency of GADD45B functions between in vitro cellular-level and in vivo tissue-level may be due to complex micro-environment in human body and the resulting abnormal gene expression. The potential mechanism needs for further exploration.

Because the colon and rectum are important digestive organs, the intestinal mucosa can be easily damaged by various factors [29-31]. The human CRC-prone disorders may contribute to the risk of CRC through the accumulation of specific products resulting from DNA damage. In our study, we found that CRC had a high expression of GADD45B, which is involved in the regulation of cell growth and apoptosis. This result suggested that CRC cells might accumulate a certain amount of DNA damage, leading to dysfunction and overexpression of GADD45B. In this scenario, under chronic genotoxic stress, the failure to appropriately repair DNA damage and control growth may contribute to colorectal carcinogenesis.

In human solid tumors, DNA damage and repair defects that lead to tumorigenesis usually involve multiple factors. Defects in functional p53, p21 (Cdkn1a), or growth suppression genes, such as those of the GADD45 gene family, could be involved [32]. p53 is the most commonly mutated gene in cancer, exerting its activity by binding DNA response elements and regulating the transcription of specific genes in response to various stimuli, thus directing cells toward cell cycle arrest or apoptosis [33]. Because p53 functions mainly as a transcription factor, it is important to explore the genes regulated by $\mathrm{p} 53$ that contribute to the regulation of apoptosis. In this study, we investigated how the changes of GADD45B expression influence apoptosis-related proteins expression. Our results showed that transfection with pEGFP-N1-GADD45B in SW480 led to an increase in P53, Bax and cleavage of PARP, as well as a decrease in Bcl-2 and unactivated caspase-3. We postulated that GADD45B-induced apoptosis may be associated with the p53-Bax mitochondrial apoptotic pathway. As apoptotic pathways are frequently altered in tumor progression, proteins associated with this pathway may have potential as prognostic biomarkers. Like other researches, we have shown pro-survival function of $\mathrm{Bcl}-2$, pro-apoptotic function of Bax, and elevated expression of P53 and caspase 3 in CRC tissues and ANCT
[34-36]. Determination of the tumors ability to undergo apoptosis holds immense potential as a new prognostic marker for CRC.

Cancer can be viewed as the result of a succession of genetic changes during which a normal cell is transformed into a malignant one. Apoptosis is intimately connected with the elimination of potentially malignant cells, hyperplasia and tumor progression [37]. The abundance of literature suggests that defects along apoptotic pathways play a crucial role in carcinogenesis. GADD45B, as a tumor suppressor potentially through the p53-mediated apoptotic pathways, is paradoxically overexpressed in CRC and as such may play an unappreciated role in tumorigenesis. Defects in this gene might have broken some kind of balance of proapoptotic and anti-apoptotic proteins contributing to evasion of apoptosis and carcinogenesis.

Several studies have reported that GADD45B was decreased in human hepatocellular carcinoma (HCC) $[8,38]$. Compared with the high levels of staining in colon cancer, breast cancer, prostate cancer, lymphoma, squamous cell carcinoma, and leiomyosarcoma, the under-expression of GADD45B was specific to liver cancer. As a novel pituitary tumor suppressor, microarray data showed the loss of GADD45B in gonadotrope tumors where its repression modulates cell proliferation, survival, and tumorigenicity [6]. The hierarchical clustering of 19 pancreatic neuroendocrine tumors (PNETs) revealed that GADD45B was one of the most highly upregulated genes in the malignant group of PNETs [39]. Therefore, there is still controversy regarding the expression and function of GADD45B in various tumors. Abnormal expression of GADD45B is similar to tumor suppressor p53 and phosphatase and tensin homologue (PTEN), both of which showing high expression in some head and neck cancers, and mammary cancer [40-42]. Further investigations are needed to determine the underlying mechanisms behind the dysfunction of GADD45B and CRC tumorigenesis.

\section{Conclusion}

In this study, GADD45B was significantly overexpressed in CRC compared with ANCT. Our results suggest that increased expression of GADD45B may play an important role in CRC carcinogenesis and be used as a useful prognostic marker in future. Expression of GADD45B in CRC was abnormal; this gene may lose its normal functions as a tumor suppressor gene. We postulate that GADD45B may have undergone mutation, promotor hyper-methylation of the $\mathrm{CpG}$ islands or other molecular biology changes which need further investigation.

\section{Abbreviations}

CRC: Colorectal carcinoma; ANCT: Adjacent noncancerous tissues; GADD45B: The growth arrest DNA damage-inducible, beta; 
HCC: Hepatocellular carcinoma; PNET: Pancreatic neuroendocrine tumors; PTEN: Phosphatase and tensin homologue.

\section{Competing interests}

The authors declare that they have no competing interests.

\section{Authors' contributions}

$X Z$ and $X D$ conceived and designed the study. LW and XX performed the experiments. LW, XX, and DL analyzed the data. YC, YW, PW, SN and CT contributed reagents, materials, and analysis tools. LW and XX wrote the paper. All authors read and approved the final manuscript.

\section{Acknowledgements}

We acknowledge American Journal Experts for significant revision of the manuscript. This work was granted by Science and Technology Commission of Shanghai Municipality (No.10DJ1400501).

\section{Author details}

'Department of Pathology, Fudan University Shanghai Cancer Center, Shanghai 200032, China. ${ }^{2}$ Department of Oncology, Shanghai Medical College, Fudan University, Shanghai 200032, China. Institute of Pathology, Fudan University, Shanghai 200032, China. ${ }^{4}$ Institutes of Biomedical Sciences, Fudan University, Shanghai 200032, China. ${ }^{5}$ Department of Oncology, Shanghai Xuhui District Center Hospital, Shanghai 200031, China. ${ }^{6} \mathrm{Cancer}$ Research Institute, Fudan University Shanghai Cancer Center, Shanghai 200032, China.

\section{Received: 11 July 2012 Accepted: 18 October 2012}

Published: 30 October 2012

\section{References}

1. Center MM, Jemal A, Ward E: International trends in colorectal cancer incidence rates. Cancer Epidemiol Biomarkers Prev 2009, 18:1688-1694.

2. Harpaz N, Polydorides AD: Colorectal dysplasia in chronic inflammatory bowel disease: pathology, clinical implications, and pathogenesis. Arch Pathol Lab Med 2010, 134:876-895.

3. Campos FG, Logullo WA, Kiss DR, Waitzberg DL, Habr-Gama A, Gama-Rodrigues J: Diet and colorectal cancer: current evidence for etiology and prevention. Nutr Hosp 2005, 20:18-25.

4. Liebermann DA, Hoffman B: Myeloid differentiation (MyD)/growth arrest DNA damage (GADD) genes in tumor suppression, immunity and inflammation. Leukemia 2002, 16:527-541.

5. Liebermann DA, Hoffman B: Myeloid differentiation (MyD) primary response genes in hematopoiesis. Blood Cells Mol Dis 2003, 31:213-228.

6. Michaelis KA, Knox AJ, Xu M, Kiseljak-Vassiliades K, Edwards MG, Geraci M, Kleinschmidt-DeMasters BK, Lillehei KO, Wierman ME: Identification of growth arrest and DNA-damage-inducible gene beta (GADD45beta) as a novel tumor suppressor in pituitary gonadotrope tumors.

Endocrinology 2011, 152:3603-3613.

7. Ou DL, Shen YC, Yu SL, Chen KF, Yeh PY, Fan HH, Feng WC, Wang CT, Lin LI, Hsu C, Cheng AL: Induction of DNA damage-inducible gene GADD45beta contributes to sorafenib-induced apoptosis in hepatocellular carcinoma cells. Cancer Res 2010, 70:9309-9318.

8. Qiu W, David D, Zhou B, Chu PG, Zhang B, Wu M, Xiao J, Han T, Zhu Z, Wang T, Liu X, Lopez R, Frankel P, Jong A, Yen Y: Down-regulation of growth arrest DNA damage-inducible gene 45beta expression is associated with human hepatocellular carcinoma. Am J Pathol 2003, 162:1961-1974.

9. Lin B, Utleg AG, Gravdal K, White JT, Halvorsen OJ, Lu W, True LD, Vessella R, Lange PH, Nelson PS, Hood L, Kalland KH, Akslen LA: WDR19 expression is increased in prostate cancer compared with normal cells, but low-intensity expression in cancers is associated with shorter time to biochemical failures and local recurrence. Clin Cancer Res 2008, 14:1397-1406.

10. Halvorsen OJ, Rostad K, Oyan AM, Puntervoll H, Bo TH, Stordrange L, Olsen S, Haukaas SA, Hood L, Jonassen I, Kalland KH, Akslen LA: Increased expression of SIM2-s protein is a novel marker of aggressive prostate cancer. Clin Cancer Res 2007, 13:892-897.
11. Bustin SA: Absolute quantification of mRNA using real-time reverse transcription polymerase chain reaction assays. J Mol Endocrinol 2000, 25:169-193.

12. Skirnisdottir I, Sorbe B, Seidal T: P53, bcl-2, and bax: their relationship and effect on prognosis in early stage epithelial ovarian carcinoma. Int J Gynecol Cancer 2001, 11:147-158.

13. Liu $X$, Cai H, Huang H, Long $Z$, Shi $Y$, Wang $Y$ : The prognostic significance of apoptosis-related biological markers in Chinese gastric cancer patients. PLoS One 2011, 6:e29670.

14. Czabotar PE, Lessene $\mathrm{G}: \mathrm{Bcl}-2$ family proteins as therapeutic targets. Curr Pharm Des 2010, 16:3132-3148.

15. Chen W, Gao N, Shen Y, Cen JN: Hypermethylation downregulates Runx3 gene expression and its restoration suppresses gastric epithelial cell growth by inducing p27 and caspase 3 in human gastric cancer. J Gastroenterol Hepatol 2010, 25:823-831.

16. Fearon ER: Molecular genetics of colorectal cancer. Annu Rev Pathol 2011, 6:479-507.

17. O'Connell MJ, Lavery I, Yothers G, Paik S, Clark-Langone KM, Lopatin M, Watson D, Baehner FL, Shak S, Baker J, Cowens JW, Wolmark N: Relationship between tumor gene expression and recurrence in four independent studies of patients with stage II/III colon cancer treated with surgery alone or surgery plus adjuvant fluorouracil plus leucovorin. J Clin Oncol 2010, 28:3937-3944.

18. Zhang D, Salto-Tellez M, Putti TC, Do E, Koay ES: Reliability of tissue microarrays in detecting protein expression and gene amplification in breast cancer. Mod Pathol 2003, 16:79-84

19. Schmidt LH, Biesterfeld S, Kummel A, Faldum A, Sebastian M, Taube C, Buhll $\mathrm{R}$, Wiewrodt R: Tissue microarrays are reliable tools for the clinicopathological characterization of lung cancer tissue. Anticancer Res 2009, 29:201-209.

20. Takekawa M, Saito H: A family of stress-inducible GADD45-like proteins mediate activation of the stress-responsive MTK1/MEKK4 MAPKKK. Cell 1998, 95:521-530.

21. Yang Z, Song L, Huang C: Gadd45 proteins as critical signal transducers linking NF-kappaB to MAPK cascades. Curr Cancer Drug Targets 2009, 9:915-930.

22. Liebermann DA, Tront JS, Sha X, Mukherjee K, Mohamed-Hadley A, Hoffman B: Gadd45 stress sensors in malignancy and leukemia. Crit Rev Oncog 2011, 16:129-140.

23. Ju S, Zhu Y, Liu L, Dai S, Li C, Chen E, He Y, Zhang X, Lu B: Gadd45b and Gadd $45 \mathrm{~g}$ are important for anti-tumor immune responses. Eur J Immunol 2009, 39:3010-3018.

24. Liebermann DA, Hoffman B: Gadd45 in the response of hematopoietic cells to genotoxic stress. Blood Cells Mol Dis 2007, 39:329-335.

25. Higgs MR, Lerat H, Pawlotsky JM: Downregulation of Gadd45beta expression by hepatitis $C$ virus leads to defective cell cycle arrest. Cancer Res 2010, 70:4901-4911.

26. Jiang C, Zhou B, Fan K, Heung E, Xue L, Liu X, Kirschbaum M, Yen Y: A sequential treatment of depsipeptide followed by 5 -azacytidine enhances Gadd45beta expression in hepatocellular carcinoma cells. Anticancer Res 2007, 27:3783-3789.

27. Tenta R, Katopodis H, Chatziioannou A, Pilalis E, Calvo E, Luu-The V, Labrie F, Kolisis F, Koutsilieris M: Microarray analysis of survival pathways in human PC-3 prostate cancer cells. CANCER GENOMICS PROTEOMICS 2007, 4:309-318.

28. Hu Y, Sun H, Drake J, Kittrell F, Abba MC, Deng L, Gaddis S, Sahin A, Baggerly K, Medina D, Aldaz CM: From mice to humans: identification of commonly deregulated genes in mammary cancer via comparative SAGE studies. Cancer Res 2004, 64:7748-7755.

29. Gingras D, Beliveau R: Colorectal cancer prevention through dietary and lifestyle modifications. Cancer Microenviron 2011, 4:133-139.

30. Abbass K, Gul W, Beck G, Markert R, Akram S: Association of Helicobacter pylori infection with the development of colorectal polyps and colorectal carcinoma. South Med J 2011, 104:473-476.

31. Uronis JM, Muhlbauer M, Herfarth HH, Rubinas TC, Jones GS, Jobin C: Modulation of the intestinal microbiota alters colitis-associated colorectal cancer susceptibility. PLoS One 2009, 4:e6026.

32. Smith ML, Ford JM, Hollander MC, Bortnick RA, Amundson SA, Seo YR, Deng CX, Hanawalt PC, Fornace AJ: p53-mediated DNA repair responses to UV radiation: studies of mouse cells lacking p53, p21, and/or gadd45 genes. 
Mol Cell Biol 2000, 20:3705-3714.

33. Itahana K, Dimri G, Campisi J: Regulation of cellular senescence by p53. Eur J Biochem 2001, 268:2784-2791.

34. Hector S, Prehn JH: Apoptosis signaling proteins as prognostic biomarkers in colorectal cancer: a review. Biochim Biophys Acta 2009, 1795:117-129.

35. Krajewska M, Kim H, Kim C, Kang H, Welsh K, Matsuzawa S, Tsukamoto M, Thomas RG, Assa-Munt N, Piao Z, Suzuki K, Perucho M, Krajewski S, Reed JC: Analysis of apoptosis protein expression in early-stage colorectal cancer suggests opportunities for new prognostic biomarkers. Clin Cancer Res 2005, 11:5451-5461.

36. Nehls $\mathrm{O}$, Okech $\mathrm{T}$, Hsieh $\mathrm{C}$, Enzinger $\mathrm{T}$, Sarbia M, Borchard $\mathrm{F}$, Gruenagel HH, Gaco V, Hass HG, Arkenau HT, Hartmann JT, Porschen R, Gregor M, Klump B: Studies on $\mathrm{p} 53, \mathrm{BAX}$ and $\mathrm{BCl}-2$ protein expression and microsatellite instability in stage III (UICC) colon cancer treated by adjuvant chemotherapy: major prognostic impact of proapoptotic BAX. Br J Cancer 2007, 96:1409-1418

37. Hanahan D, Weinberg RA: The hallmarks of cancer. Cell 2000, 100:57-70.

38. Qiu W, Zhou B, Zou H, Liu X, Chu PG, Lopez R, Shih J, Chung C, Yen Y: Hypermethylation of growth arrest DNA damage-inducible gene 45 beta promoter in human hepatocellular carcinoma. Am J Pathol 2004, 165:1689-1699.

39. Duerr EM, Mizukami Y, Ng A, Xavier RJ, Kikuchi H, Deshpande V, Warshaw AL, Glickman J, Kulke MH, Chung DC: Defining molecular classifications and targets in gastroenteropancreatic neuroendocrine tumors through DNA microarray analysis. Endocr Relat Cancer 2008, 15:243-256.

40. Jamaly S, Khanehkenari MR, Rao R, Patil G, Thakur S, Ramaswamy P, Ajaikumar BS, Sahoo R: Relationship between p53 overexpression, human papillomavirus infection, and lifestyle in Indian patients with head and neck cancers. Tumour Biol 2012, 33:543-550.

41. Monteiro LS, Diniz-Freitas M, Garcia-Caballero T, Warnakulasuriya S, Forteza J, Fraga M: Combined cytoplasmic and membranous EGFR and p53 overexpression is a poor prognostic marker in early stage oral squamous cell carcinoma. J Oral Pathol Med 2012, 41:559-567.

42. Zhao H, Cui Y, Dupont J, Sun H, Hennighausen L, Yakar S: Overexpression of the tumor suppressor gene phosphatase and tensin homologue partially inhibits wnt-1-induced mammary tumorigenesis. Cancer Res 2005, 65:6864-6873.

doi:10.1186/1479-5876-10-215

Cite this article as: Wang et al:: Abnormal expression of GADD45B in human colorectal carcinoma. Journal of Translational Medicine 2012 10:215

\section{Submit your next manuscript to BioMed Central and take full advantage of:}

- Convenient online submission

- Thorough peer review

- No space constraints or color figure charges

- Immediate publication on acceptance

- Inclusion in PubMed, CAS, Scopus and Google Scholar

- Research which is freely available for redistribution 